\title{
Correction to: Total Harmonic Distortion Performance in PV Systems Using Fuzzy Logic Controller
}

\author{
Ahmed Ali, Bhekisipho Twala, Tshilidzi Marwala, \\ and Ilyes Boulkaibet
}

\section{Correction to:}

Chapter "Total Harmonic Distortion Performance in PV Systems Using Fuzzy Logic Controller" in:

M. Chadli et al. (Eds.): Advanced Control Engineering Methods in Electrical Engineering Systems, LNEE 522, https://doi.org/10.1007/978-3-319-97816-1_25

The original version of the chapter was inadvertently published with incorrect fourth author "Ilyes Boulkabet", which should be corrected to read as "Ilyes Boulkaibet" in chapter "Total Harmonic Distortion Performance in PV Systems Using Fuzzy Logic Controller". The correction chapter and the book have been now updated with the change. 